\title{
Local University Intellectual Property Management Specification
}

\author{
Zhao Gui ${ }^{1,}$, , Zhang Tao ${ }^{2, b}$, Zhu Guojun ${ }^{3, c}$,Luo Hongmei ${ }^{4, d}$, Zhang Hongyuan ${ }^{5, e}$ \\ ${ }^{1}$ Huaihai Institute of Techology, Lianyungang, Jiangsu, China \\ ${ }^{2}$ Huaihai Institute of Techology, Lianyungang, Jiangsu, China \\ ${ }^{3}$ Huaihai Institute of Techology, Lianyungang, Jiangsu, China \\ a706570805@qq.com, b346028290@qq.com, '357866734@qq.com
}

\begin{abstract}
Keywords: Local universities; intellectual property; management standards.
Abstract. Based on the analysis of the problems existing in chinese intellectual property management in Colleges and universities, combined with intellectual property management in the Huaihai Institute of technology, enterprise standards in Lianyungang City. It is pointed out that necessity for colleges and universities to carry out standards, Huaihai Institute of technology, intellectual property management standards are formulated, for the local high school to develop intellectual property management practices to provide reference.
\end{abstract}

\section{Introduction}

The progress of world science and technology change rapidly today, the rapid development of knowledge economy, intellectual property resources are the core elements of a national strategy to enhance the international competitiveness, seek development, playing an increasingly important role in the economic and social development. The national intellectual property strategy outline published in June 2008 formally established the strategy of intellectual property rights as a national strategy and implemented the strategy of innovation driven development. Scientific and technological innovation is the strategic support to improve social productive forces and overall national strength, and must be placed in the core position of the overall development of the country. Party's eighteen report pointed out: "improve the scientific and technological innovation evaluation criteria, incentive mechanism, transformation mechanism.". Implementing the strategy of intellectual property rights and strengthening the protection of intellectual property rights. Promote the efficient allocation and integration of innovation resources, and bring the whole society wisdom and strength to innovation and development.

This paper studies the regulations of intellectual property management in local colleges and universities, strengthen the use of patent information, enhance the level of scientific research and innovation, avoid the risk of intellectual property rights by promoting research cooperation, realize the value of intellectual property rights, and promote the healthy development of the work of intellectual property management in local universities.

\section{Concepts related to intellectual property management}

\section{University Intellectual Property Management}

Intellectual property management in Colleges and universities is refers to the university according to the general principles of intellectual property management, make full use of the intellectual property system, the management mechanism of intellectual property rights, intellectual property work and school personnel training, scientific research, social services and cultural innovation work to co-ordinate the implementation of intellectual property management, whole process management, improve the quality of intellectual property rights improve the ability of technological innovation. 1999 issued by the Ministry of education No. 3 "university intellectual property management regulations" and the Ministry of education in 2004 "on the further strengthening of intellectual property rights in Colleges and universities work opinions" is still the current university intellectual property management guidance documents. 


\section{Intellectual property management}

(1) Intellectual property management of enterprises

The so-called "standards", for enterprise organizations, that is, the implementation of the "enterprise intellectual property management norms" national standards. Enterprise intellectual property management standards national standards formulated by the State Intellectual Property Office, on March 1, 2013, by the State Administration of Quality Supervision Inspection and quarantine, the National Standardization Management Committee approved the promulgation and implementation of the standard number is GB/T29490-2013. Mark can establish a standard system of intellectual property rights to help enterprises, strengthen the enterprise intellectual property work guidance, implementation of intellectual property strategy and scientific management, improve the ability of market competition at home and abroad.

(2) The implementation of intellectual property management in universities

"Standards" for colleges and universities, that is, the implementation of the "university intellectual property management norms" national standards. "Intellectual property management standards" can further guide the work of intellectual property rights, regulate the use of University, promotion, protection of intellectual property rights, and the international competitiveness, ultimately promoting technological innovation and intellectual property assets. State Intellectual Property Office in July 1, 2015, the "university intellectual property management specification (Draft)" to solicit public opinions, this is the "standard" enterprise intellectual property management after another intellectual property management norms. "University intellectual property management specification (Draft)" proposed from the aspects of intellectual property management, file management responsibility, resource management, intellectual property management in the whole process, key aspects of the protection of intellectual property rights, intellectual property rights management in higher schools.

\section{The standard of enterprise implementation in Lianyungang}

With the rapid development of the national economy, the future development of the enterprise resource constraints, environmental constraints faced by the contradictions have become increasingly prominent, the transformation of economic growth mode, adjust and optimize industrial structure, improve the capability of independent innovation is the only way which must be passed the enterprise economic development. Chinese enterprises can not fully understand connotation of intellectual property rights, management is not in place, weak awareness of intellectual property rights, lack of talents, weak ability of independent innovation of intellectual property rights, low output, intellectual property protection ability, marketing ability is weak. Therefore, through effective intellectual property management to enhance the independent innovation ability of enterprises, and to realize the transformation of enterprise development mode to innovation driven, it has become the urgent task of enterprise intellectual property management.

Lianyungang existing enterprises to standardize the management of intellectual property rights demonstration, set up a record enterprise 183, through the acceptance of 25 , advanced units 12 , through the national certification body certification 7. "Standard" enterprise intellectual property management standards by government departments to actively guide and promote intellectual property intermediary service agencies to provide advice and services, the majority of enterprises and to participate in the voluntary implementation of the principles of organization and implementation. Lianyungang city enterprises to participate in standards, not only can obtain government funding and government support, also make the management of the enterprise intellectual property rights system to promote the visibility and recognition of the society and make the enterprise more competitive advantage in the market competition, and provide a reference for the local colleges and universities to carry out intellectual property management practices. 


\section{Present situation and problems of intellectual property management in Colleges and Universities}

At present, the number of patent applications in Colleges and universities in China has increased considerably, and the management tasks have been increasing. The rate of patent maintenance in universities has generally been around 3 years, and there is a lack of patent management models suitable for different colleges and universities. Abroad, the Stanford University OTL, TLO of the University of Tokyo, is the internal organization management mode; "school license America" (CLC) is outsourced to the management mode of professional institutions, intellectual property management limited liability company of University of Wisconsin WARF, University of Cambridge is a peripheral organization management mode. They have detailed management processes, transformation considerations, and professional service teams. According to the national development and Reform Commission report, in 2013 the United States patent transaction average price of \$220 thousand, scientific research institutions, University Patent conversion rate, the United States, European Union, Japan in $40 \%$, China is $10 \%$, the main difference is not our ability to use in the innovation and management ability, is. The purpose of intellectual property management in Colleges and universities is to have more high-quality patents and to promote more innovation in return. It is the creation, management and application of patents.At present, the main problems existing in the management of intellectual property in Colleges and universities are as follows:

\section{The intellectual property strategy and the protection consciousness are weak}

Although some colleges and universities to establish a special intellectual property management organization, strengthening the work of intellectual property management, but mostly no intellectual property into the strategic development of the school, did not play the biggest role in the regional economy; scientific research teachers and university management understanding of the system of intellectual property protection and far not enough, lack of legal awareness, poor awareness of market competition. Taking Huaihai Institute of Techology as an example, the core of scientific research of many scientific research teachers is project approval, scientific research reward and title promotion, which results in the failure to form intellectual property rights in a large amount of scientific research.

\section{Lack of perfect management system}

Patent management is the core content of intellectual property management in Colleges and universities, "published since 1999, the Ministry of education of intellectual property protection and management regulations" since there are still many colleges and universities lack of management system and operation mechanism. At present, Huaihai Institute of Techology business ownership of intellectual property rights in technology and industry, there is no intellectual property agency established independent intellectual property rights, lack of professional talent, work mode is mainly based on the statistics of various types of patents, patent review format, and the establishment and management of the protection of intellectual property rights and the transformation and application of system services perfect, resulting in the loss of intellectual property is a common phenomenon, the intellectual property management level and the ability to be improved.

\section{Lack of operation mechanism, low conversion rate}

The achievement transformation of intellectual property rights refers to a series of activities to improve the productivity and economic level through the application and promotion of intellectual property rights through the formation of new technologies, new products or new industries. At present, many colleges and universities not only lack of effective policy guidance and incentive and incentive mechanism, but also the lack of scientific evaluation and application system, the patent management work are in application management, which leads to the real value of intellectual property does not play out. For example, Huaihai Institute of Techology, nearly 5 years, although the patent applications and licensing volume increased significantly, but the rate of conversion of less than $10 \%$, the patent effective implementation rate is low, most patents are only a worthless right. 


\section{The necessity of standardizing intellectual property management in Local Universities}

Intellectual property management is the basis of intellectual property related follow-up work, good management can help improve the school's scientific research ability and comprehensive strength, the intellectual property management level of most universities in our country is still backward. With the "standard" enterprise intellectual property management standards to promote the work of the State Intellectual Property Office, 2014 designated the Jiangsu University carried out a "university intellectual property management standards" of the preparation work, Jiangsu currently has 9 colleges and universities to participate in the pilot work, compared with the enterprise intellectual property standards, intellectual property rights and development standards for local colleges and universities benefit is self-evident:

\section{Help colleges and universities upgrade strategic height}

One of the key universities is the intellectual property standards of intellectual property strategy, understand the national planning requirements, by implementing strategic planning of the school with the national standards, with the interests of the society and country docking, to help the universities to enhance the strategic height.

\section{Further stimulate the ability of independent innovation and management}

At present, colleges and universities are faced with increasingly fierce competition at home and abroad, and the core competitiveness of colleges and universities is mainly embodied in technology, talent and management. Through the implementation, the development of intellectual talent, build and cultivate a team with intellectual property management and practice ability of professional personnel, can enhance the effective control of technology, strengthen the knowledge innovation ability of University; through the implementation, contribute to the scientific research personnel in Colleges and universities to enhance the awareness of intellectual property rights, innovation consciousness, stimulate researchers create enthusiasm invention, enhance innovation and initiative. Effectively improve the ability of intellectual property protection in Colleges and universities

Through the implementation, the relevant management mechanism in Colleges and universities to establish a set of effective intellectual property protection system, can help enhance the protection consciousness of intellectual property in universities, enhance the intellectual property rights of the early warning ability, the formation of intellectual property identification mechanism against infringement of our intellectual property rights.

\section{Strategies for improving the management standards of intellectual property rights in Local Universities -- Taking Huaihai Institute of Techology as an example}

Through the work of intellectual property rights and the school personnel training, scientific research, social services and manpower management, realize the whole process of intellectual property management; intellectual property rights through the improvement of information utilization mechanism, improve the quality of intellectual property rights, improve the ability of technological innovation; through innovations and marketization of property rights, the establishment of technological innovation incentive mechanism, to promote innovation value realization. As follows: Research objectives

Market oriented, standardize property management Huaihai Institute of Techology knowledge, strengthen patent information utilization, enhance the level of scientific research and innovation, avoid the risk of intellectual property rights by promoting research cooperation, realize the value of intellectual property rights, promote the healthy development of the school.

\section{Research content:}

\section{( 1 ) Organization construction:}

(1)Top management: the president's decision making layer must have strong intellectual property rights awareness and ideas. 
(2) Management Committee: the Intellectual Property Management Commission, which consists of top management, discipline experts and management representatives, is established, and is fully responsible for the practice of intellectual property management.

(3) Intellectual property rights management: Science and Technology Department set up patent management section or separate intellectual property management office.

(4) Technology transfer institutions: establish technology transfer institutions and provide full-time staff.

( 2 ) Policy document planning:

The establishment of intellectual property management documents necessary, to encourage schools to effectively manage intellectual property by means of information management, file management documents, including: intellectual property intellectual property management system of intellectual property management procedures, record file.

\section{( 3 ) Workflow design:}

(1)The topic and project: A collection of information channels, to research in the field of patent information acquisition; classifying information filtering classification processing, grasp the development trend of technology; project, thesis, patent information analysis; intellectual property rights should be clear project goals project, contract of intellectual property right; the person in charge of the project train and remind; record file form: patent information analysis report, intellectual property, intellectual property ownership certificate.

(2) Project implementation: The patent information tracking project research, adjust project research direction and content of the project research results; timely evaluation and confirmation, determine the formation of intellectual property protection, timely; in R \& D activities, to avoid infringement of intellectual property rights, to keep the R \& D process records, the implementation of effective management.

(3) Check before acceptance : The management and protection of knowledge areas are evaluated in the direction of application.

\section{( 4 ) Transformation of scientific research achievements:}

To evaluate the intellectual property from the legal, technical and market dimensions, determine the maintenance period, the establishment of state control procedures, the establishment of intellectual property right up procedures, classified management of intellectual property rights, intellectual property promotion operations to achieve the value of intellectual property rights, enhance the quality of intellectual property rights; establish scientific research personnel of intellectual property rights incentive mechanism, and consider the license, transfer and investment shares and other intellectual property rights operation mode; to do the work of intellectual property protection, to prevent the loss of intellectual property rights, reducing the risk of intellectual property rights.

\section{( 5 ) Condition Guarantee}

(1) Infrastructure: Provide relevant resources as needed to ensure the operation of the intellectual property management system.

(2)Financial resources: Regular budget costs for intellectual property rights shall be established.

(3) Information resources: Do a good job of intellectual property information collection, processing, utilization and other management.

\section{( 6 ) Evaluation and improvement}

(1) Performance evaluation: Intellectual property rights (patents, papers, monographs, etc.) into the technical titles, academic level, annual performance evaluation 
(2) Check: Monitor and improve the inspection and supervision mechanism of the establishment of intellectual property rights, to ensure the effective implementation of the intellectual property system; the management system of intellectual property rights found, suggestions on the improvement of intellectual property management system; to have not reached the expected requirements of the project or the staff, put forward opinions and urge.

\section{Conclusions}

The intellectual property management regulations of Huaihai Institute of Techology can be used for reference with other local colleges and universities of the same type and scale in Huaihai Institute of Techology, so as to establish a practical intellectual property management system. The management of intellectual property rights in Institutions of higher learning is a new thing, and the complexity depends on many factors, such as the system, scale and direction of scientific research. It needs further exploration and improvement in the future scientific research practice.

\section{Acknowledgements}

The project was supported by research program of phinosophy and social science of Jiangsu highschool(2015SJD681);open program of marine ecomomics research center of JIangsu ( HJ14007 ) ; the Jiangsu Province R\&D Institute of Marine Resources ( JSIMR201424 )

\section{References}

[1] Hu Jintao. Unswervingly march along the road of socialism with Chinese characteristics and strive for building a moderately prosperous society in an all-round way -- report at the eighteenth National Congress of the Communist Party of China

[2] Zhu Yan. Research on mechanism and implementation of university intellectual property rights implementation based on game theory [D]. Beijing: Beijing Jiaotong University, 2015:1-6

[3] Liu Yongjun. Innovative ideas of enterprise intellectual property standard implementation [J]. legal system and economy, 2015,6 (410):61-63.

[4] Chen Haiqiu, Liu Yingqing. On the objectives, contents and measures of intellectual property management in Institutions of higher learning [J]. Journal of Beihang University, 2003, 16 (4):21-23. 